\title{
Effect of iron deprivation on surface composition and virulence determinants of Candida albicans
}

\author{
Simon P. SweEt and L. Julia Douglas* \\ Department of Microbiology, University of Glasgow, Glasgow G12 8QQ, UK
}

(Received 13 August 1990; revised 26 November 1990; accepted 3 December 1990)

\begin{abstract}
Six strains of Candida albicans were grown in defined medium which had been deferrated by ion-exchange chromatography and then supplemented with $\mathrm{FeCl}_{3}$ to give iron concentrations ranging from $0.026 \mu \mathrm{M}$ to $0.8 \mu \mathrm{M}$. Growth in $0.026 \mu \mathrm{M}$-iron (measured as increase in biomass) was reduced by $26-59 \%$ as compared with that in excess $(0.8 \mu \mathrm{M})$ iron. With five of the strains, adhesion to buccal epithelial cells was maximal after growth in 0.2$0.4 \mu \mathrm{M}$-iron, but strain GDH 2023 adhered best when grown in $0.026 \mu \mathrm{M}$-iron. Differences in yeast cell-wall composition were revealed by Zymolyase treatment of whole cells and by ${ }^{125}$ I-labelling of surface proteins. SDSPAGE of iodinated proteins, followed by autoradiography, showed quantitative but no qualitative differences in protein profiles of iron-deficient and iron-replete organisms. The ability of all strains to form germ tubes in serum was near-maximal after growth in $0 \cdot 2-0 \cdot 4 \mu \mathrm{M}$-iron but was inhibited by up to $93 \%$ following growth in lower concentrations. These results indicate that expression of important virulence attributes by $C$. albicans is highly dependent on available iron and that expression in vivo may therefore be significantly different from that observed under conventional laboratory conditions.
\end{abstract}

\section{Introduction}

Infections caused by the opportunistic pathogen Candida albicans are becoming increasingly important but their pathogenesis is poorly understood at the molecular level (Odds, 1988). One factor likely to influence the progress of infection is the ability of the yeast to adapt to the ironrestricted environment of its host. Although there is an abundance of iron in the human body, it is mainly located intracellularly (as haem or ferritin), where it is relatively inaccessible to micro-organisms. Extracellular iron exists tightly complexed to the iron-binding glycoproteins transferrin and lactoferrin, and the amount of free iron present in body fluids is insufficient to sustain microbial growth. Pathogenic micro-organisms capable of multiplying successfully under these conditions must therefore possess special mechanisms for assimilating this essential element (Finkelstein et al., 1983; Bullen \& Griffiths, 1987). Many bacteria secrete iron-chelating compounds, known as siderophores, and synthesize envelope receptors for the uptake of iron-siderophore complexes (Neilands, 1981, 1982). Siderophore production by $C$. albicans has also been reported (Holzberg \& Artis, 1983; Ismail et al., 1985).
Iron deprivation results in significant phenotypic changes in both the metabolism and cell-surface composition of pathogenic bacteria. Its effect on the outer membrane protein composition of Gram-negative organisms has been extensively studied and there is now considerable evidence that bacteria deprived of iron in vitro or in vivo contain several outer-membrane proteins which are repressed when the same organisms are grown in complex, iron-rich media (Brown \& Williams, 1985). Synthesis of bacterial toxins can also be affected by the availability of iron; diphtheria and tetanus toxins, for example, are produced in optimal yields only during growth in low-iron media (Holmes \& Russell, 1983).

In contrast with the wealth of published data on the role of iron in bacterial infections, little is known of the mechanisms by which pathogenic yeasts adapt to iron restriction in vivo. This paper describes an investigation of the effect of iron deprivation on two postulated virulence determinants of $C$. albicans, namely its ability to adhere to epithelial cells and its propensity for germtube formation. Differences in cell-surface composition between iron-depleted yeasts and iron-sufficient organisms are also reported. 


\section{Methods}

Organisms. Six strains of $C$. albicans were used in this study. $C$. albicans NCPF 3153 was from the Mycological Reference Laboratory, Colindale Avenue, London, UK. C. albicans 'outbreak' strain, which was isolated as the causative agent of an outbreak of systemic candidosis at The London Hospital, was kindly supplied by Dr J. P. Burnie. The remaining four strains were isolated in Glasgow and are now deposited with the National Collection of Yeast Cultures (NCYC), Food Research Institute, Norwich, UK. Strains GRI 681 (NCYC 1472) and GRI 682 (NCYC 1473) were obtained from routine cervical smears taken from asymptomatic women at Glasgow Royal Infirmary; strains GDH 2346 (NCYC 1467) and GDH 2023 (NCYC 1468) were isolated at Glasgow Dental Hospital from patients with denture stomatitis. The organisms were maintained on slopes of Sabouraud dextrose agar (Difco) and subcultured monthly. Every two months the cultures were replaced by new ones freshly grown from freeze-dried stocks.

Preparation of deferrated medium. To minimize iron contamination, disposable plasticware was used wherever possible; glassware was washed with Extran $(\mathrm{BDH})$, soaked in $1 \%(\mathrm{v} / \mathrm{v}) \mathrm{HCl}$ for at least $48 \mathrm{~h}$ and rinsed extensively with distilled deionized water. The medium used was a modification of yeast nitrogen base (Difco), prepared from individual constituents and containing $50 \mathrm{~mm}$-glucose as the carbon source. Prior analysis of the medium components by graphite furnace atomic absorption spectrometry revealed that the main source of contaminating iron was monobasic potassium phosphate; this was therefore replaced by the dibasic salt which contained approximately 40-fold less iron. Deferration of the medium was accomplished by passage through columns of Chelex 100 ion-exchange resin (Bio-Rad) using procedures recommended by the manufacturer. A stock solution containing most of the medium components (except glucose, $\mathrm{MgSO}_{4}$, $\mathrm{CaCl}_{2}, \mathrm{CuSO}_{4}, \mathrm{MnSO}_{4}, \mathrm{ZnSO}_{4}$ and $\mathrm{FeCl}_{3}$, made up in distilled deionized water, was passed through a column $(2.5 \times 50 \mathrm{~cm})$ of sodiumform resin. Glucose, as a $1 \mathrm{~m}$ solution, and the distilled, deionized water to be used for diluting the concentrated medium, were passed through separate columns of sodium-form resin. Stock solutions of $\mathrm{CaCl}_{2}$ and $\mathrm{MgSO}_{4}$ were passed through columns of calcium-form and magnesium-form resin, respectively. Solutions of zinc, copper and manganese salts were not treated with Chelex 100 because they were of low concentration and contained insignificant amounts of iron. The various stock solutions were combined to give a 10 -fold concentrate of medium which was sterilized by filtration through $0.45 \mu \mathrm{m}$ Sterifil-D filter units (Sterilin) and stored at $4{ }^{\circ} \mathrm{C}$ until use.

When diluted, the medium had an iron content of $0.026 \mu \mathrm{M}$ as determined by graphite furnace atomic absorption spectrometry. It was supplemented, as indicated, by adding solutions of $\mathrm{FeCl}_{3}$ freshly prepared from a concentrated stock; storage of dilute solutions was avoided to minimize adsorption of iron to the plastic containers. In some experiments transferrin, lactoferrin or ovotransferrin (all substantially iron-free, from Sigma) were included in the medium at concentrations of between $1 \mu \mathrm{M}$ and $20 \mu \mathrm{M}$.

Growth conditions. The yeasts were grown in yeast nitrogen base medium, modified as described above, containing 0.026-0.8 $\mu \mathrm{M}$ iron Batches of medium $(20 \mathrm{ml}$, in $100 \mathrm{ml}$ acid-washed Erlenmeyer flasks) were inoculated with $10 \mu \mathrm{l}$ of yeast suspension $\left(2 \times 10^{6} \mathrm{cells} \mathrm{ml}^{-1}\right)$ to give a concentration of $10^{3}$ cells ml-1, and incubated at $37^{\circ} \mathrm{C}$ in an orbital shaker operating at 60 r.p.m. Cells were harvested after $48 \mathrm{~h}$ (stationary growth phase) and washed once in $0.15 \mathrm{M}$-phosphatebuffered saline ( $\mathrm{pH} 7.2$; PBS) at $4{ }^{\circ} \mathrm{C}$. Inocula were prepared by washing and suspending organisms freshly grown on plates of deferrated yeast nitrogen base agar in $0.03 \mathrm{M}$-citrate-buffered saline, pH 5.
Determination of dry weights. Organisms from portions $(10 \mathrm{ml})$ of $48 \mathrm{~h}$ cultures were collected on pre-weighed cellulose nitrate filters $(0.45 \mu \mathrm{m}$ pore size; $25 \mathrm{~mm}$ diam.; Whatman) and given three washes with distilled water $(5 \mathrm{ml})$. The filters were dried to constant weight at $80^{\circ} \mathrm{C}$ and the cell dry weight per $\mathrm{ml}$ of culture calculated.

Adhesion assays. Yeast adhesion to exfoliated buccal epithelial cells was determined by light microscopy as described by Douglas et al. (1981), except that a lower yeast cell concentration $\left(1 \times 10^{7}\right.$ organisms $\mathrm{ml}^{-1}$ ) was used. Epithelial cells were collected from the same healthy human donor for all experiments and before any dietary intake for that day. All assays were done in triplicate on at least three separate occasions.

Sensitivity to Zymolyase 20T. Duplicate portions $(5 \mathrm{ml})$ of yeast cell

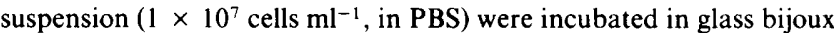
bottles at $37^{\circ} \mathrm{C}$ in an orbital shaker operating at 60 r.p.m. To one bijou (test) was added Zymolyase $20 \mathrm{~T}(0.1 \mathrm{ml}$; Miles Laboratories) to give a final concentration of $0.1 \mathrm{mg} \mathrm{ml}^{-1}$ To the other (control) suspension was added $0.1 \mathrm{ml}$ distilled water. After $60 \mathrm{~min}$ the optical densities $(520 \mathrm{~nm})$ of the suspensions were determined, and the percentage decrease in $\mathrm{OD}_{520}$ of the test suspension as compared with the control was calculated.

Production of germ tubes. Portions $(0.1 \mathrm{ml})$ of yeast suspension $\left(1 \times 10^{7}\right.$ cells $\mathrm{ml}^{-1}$, in PBS $)$ were mixed with foetal calf serum $(0.5 \mathrm{ml}$; Gibco) and PBS (0.4 ml), and a small sample of each mixture transferred to a haemocytometer. The edges of the chambers were sealed with adhesive tape to prevent drying and the haemocytometers were incubated in a humid atmosphere at $37^{\circ} \mathrm{C}$. After $2 \mathrm{~h}$ the suspensions were examined microscopically to determine the percentage of yeasts possessing germ tubes. In each case, the number of yeasts counted was 200 . Germ tubes were counted only if they were at least as long as the diameter of the mother cell.

Iodination of yeast cell-surface proteins. C. albicans GDH 2346 (100 mg wet wt cells) was transferred in PBS $(100 \mu l)$ to a glass tube precoated with $0 \cdot 1 \mathrm{mg}$ Iodogen (Pierce Chemicals). Na ${ }^{125} \mathrm{I}[20 \mu$ containing $\left.0.05 \mathrm{mCi}(1.85 \mathrm{MBq}){ }^{125} \mathrm{I}\right]$ was added and the mixture was left at room temperature with occasional shaking for $15 \mathrm{~min}$. It was then transferred to a microfuge tube containing $2.5 \mathrm{M}-\mathrm{KI}(10 \mu \mathrm{l})$ and PBS $(600 \mu \mathrm{l})$. The yeasts were washed three times with PBS $(1 \mathrm{ml})$, three times with distilled water $(1 \mathrm{ml})$, and finally boiled for $10 \mathrm{~min}$ in $2 \%(w / v)$ SDS containing $0.4 \%$ dithiothreitol $(200 \mu \mathrm{l})$. After cooling, the suspension was centrifuged and the supernatant $(100 \mu l)$ was added to a mixture of $50 \%(\mathrm{v} / \mathrm{v})$ glycerol $(10 \mu \mathrm{l})$ and $0 \cdot 2 \%$ bromophenol blue $(10 \mu \mathrm{l})$. The relative activities of the iodinated supernatants were determined in a scintillation counter so that equal amounts could be applied to polyacrylamide gels. SDS-PAGE was carried out using $10 \%$ $(\mathrm{w} / \mathrm{v})$ separating gels and $4.5 \%(\mathrm{w} / \mathrm{v})$ stacking gels. After electrophoresis, gels were dried in a slab gel drier prior to autoradiography with Hyperfilm MP (Amersham) with exposure times of 7-14 d.

\section{Results}

\section{Growth of Candida albicans in iron-restricted medium}

Initially, various methods of deferration were investigated to establish optimal iron-restricted growth conditions for C. albicans. Addition to the medium of synthetic iron chelators such as 1,10-phenanthroline or 2,2'-dipyridyl proved unsatisfactory since their inhibitory effect on 


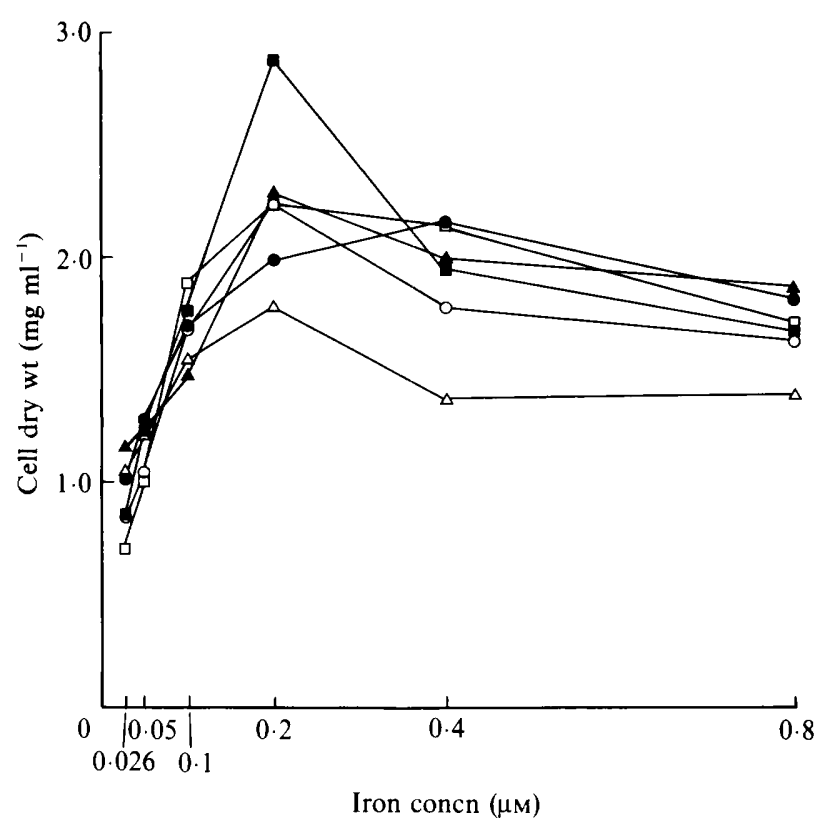

Fig. 1. Growth of six strains of $C$. albicans in medium containing different concentrations of iron. $O$, Strain GDH 2346; $\square$, strain GDH 2023; $\triangle$, strain GRI 681; , strain GRI 682; , strain NCPF 3153 ; $\boldsymbol{\Delta}$, 'outbreak' strain. The data represent mean values from three separate experiments.

growth could be reversed not only by the subsequent addition of iron but also by zinc, copper or even aluminium salts (data not shown). Surprisingly, the biological chelators transferrin, lactoferrin and ovotransferrin - which are highly specific for iron - had no effect on growth of any of the $C$. albicans strains tested at concentrations which should have elicited inhibition. The most likely explanation for this unexpected result is instability of the iron-chelator complex at $\mathrm{pH} 5.4$ (the initial $\mathrm{pH}$ value of the growth medium).

Successful deferration was accomplished by passing the medium through columns of Chelex 100 ionexchange resin. The procedure used produced medium with an iron content of $0.026 \mu \mathrm{M}$ as determined by graphite furnace atomic absorption spectrometry. This medium, supplemented as necessary with $\mathrm{FeCl}_{3}$, was used to investigate growth of six $C$. albicans strains at different iron concentrations ranging from $0.026-0.8 \mu \mathrm{M}$ (Fig. 1). With all of the strains tested the latter concentration (which is that present in complete yeast nitrogen base medium as supplied by the manufacturers, Difco) represented excess iron since adding more $\mathrm{FeCl}_{3}$ did not increase growth. However, maximal growth was obtained at lower concentrations of $0 \cdot 2-0.4 \mu \mathrm{M}$. At the lowest iron concentration tested $(0.026 \mu \mathrm{M})$, growth of the six strains was reduced by $26-59 \%$ (Fig. 1).

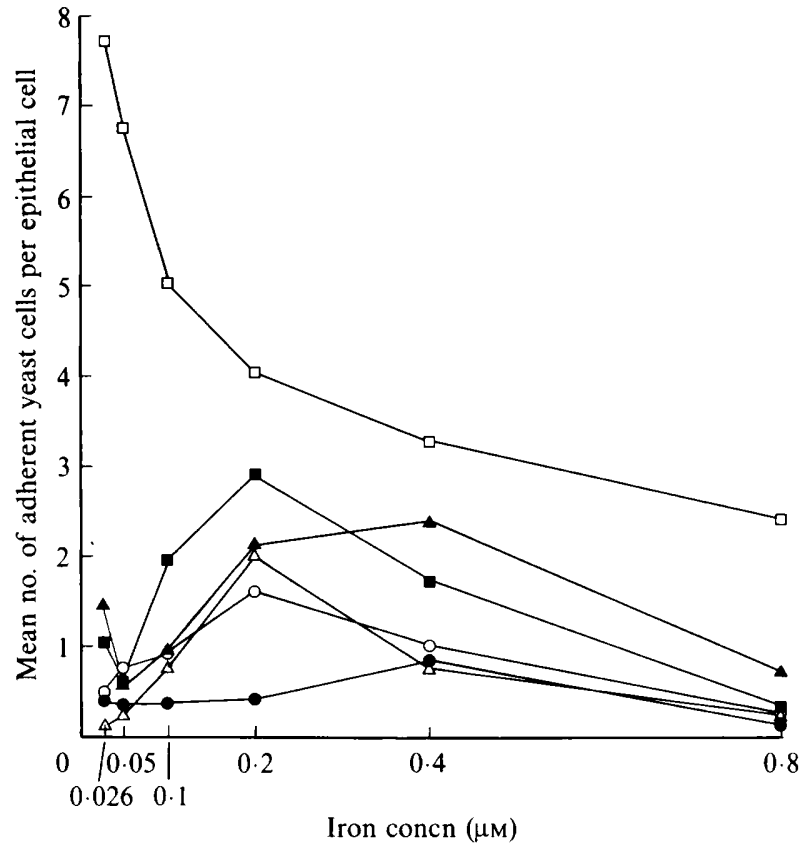

Fig. 2. Adhesion of C. albicans to buccal epithelial cells after growth in different concentrations of iron. $O$, Strain GDH 2346; $\square$, strain GDH 2023; $\triangle$, strain GRI 681;, strain GRI 682; $\boldsymbol{\square}$, strain NCPF 3153; $\Delta$, 'outbreak' strain. The data represent mean values from three separate experiments each done in triplicate.

\section{Effect of iron deprivation on yeast adhesion}

Adhesion of $C$. albicans to buccal epithelial cells in vitro was determined after growth of the yeast in medium containing different concentrations of iron. All strains showed similar patterns of adhesion (Fig. 2) with the notable exception of strain GDH 2023, which adhered in very high numbers after growth in medium with the lowest iron concentration $(0.026 \mu \mathrm{M})$. Growth of this strain at higher concentrations of iron decreased its ability to adhere by up to $64 \%$. The five other C. albicans strains adhered relatively poorly after growth in excess or limiting iron, but showed maximal adhesion when grown at iron concentrations of $0 \cdot 2-0 \cdot 4 \mu \mathrm{M}$ (Fig. 2).

\section{Effect of iron deprivation on yeast cell-surface composition}

Differences in adhesion indicate differences in yeast cellsurface composition. These were assessed initially by measuring the sensitivity of the organisms to the muralytic enzyme preparation, Zymolyase. Strain GDH 2023 appeared to be largely resistant after growth at all concentrations of iron tested (Fig. 3). The other five strains were sensitive to different degrees when grown with excess iron, but all became more resistant with 


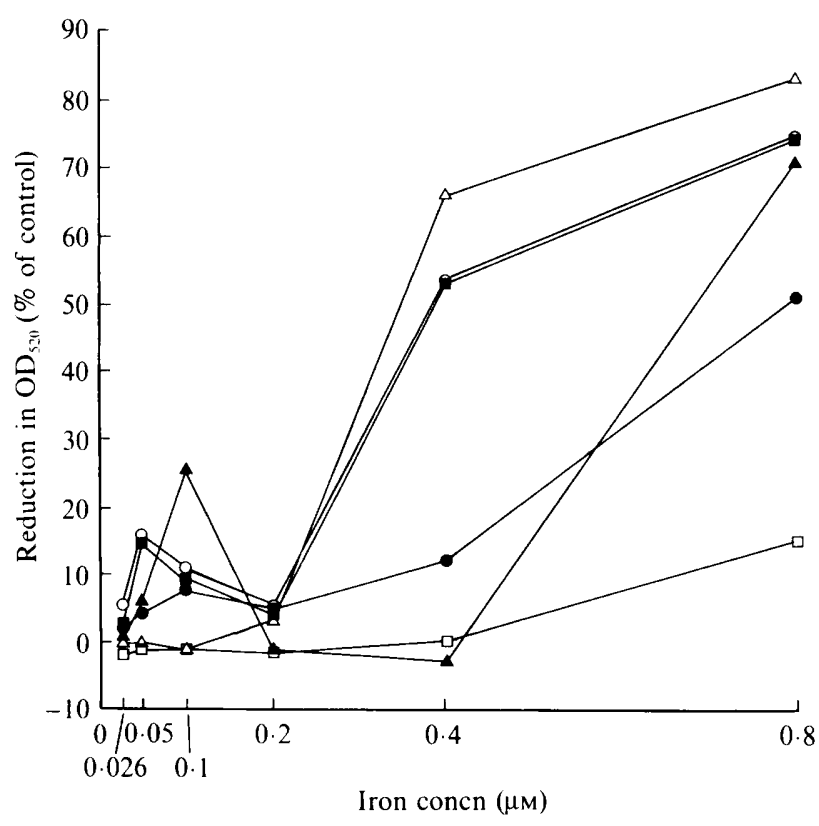

Fig. 3. Sensitivity of $C$. albicans to Zymolyase after growth in different concentrations of iron. $\bigcirc$, Strain GDH 2346; $\square$, strain GDH 2023; $\triangle$, strain GRI 681; 9 , strain GRI 682; $\mathbf{\square}$, strain NCPF 3153; $\boldsymbol{\Delta}$, 'outbreak' strain. The data represent mean values from three separate experiments.

decreasing iron concentrations. When the available iron was reduced to $0.4 \mu \mathrm{M}$ half of the strains were resistant to Zymolyase, whereas after growth with $0 \cdot 2 \mu \mathrm{M}$ iron all were resistant. Some of the strains, in particular the 'outbreak' isolate, showed slight increases in resistance at iron concentrations between 0.026 and $0.2 \mu \mathrm{M}$ (Fig. 3).

Differences in surface composition of strain GDH 2346 were further investigated by SDS-PAGE of cellwall mannoproteins following radio-iodination of whole cells. Autoradiography of gels revealed quantitative but no qualitative differences in protein profiles of yeasts grown with different concentrations of iron. Five main protein components $(16,26,39,47$ and $85 \mathrm{kDa})$ were evident in increased amounts in cells grown with $0.026 \mu$ M-iron (Fig. 4). By contrast, six components appeared in increased amounts in organisms grown with excess iron $(18,19,35,49,51$ and $64 \mathrm{kDa})$. The $19 \mathrm{kDa}$ component seemed to be present in largest amounts in organisms grown with $0 \cdot 2 \mu \mathrm{M}$ - and $0 \cdot 4 \mu \mathrm{M}$-iron (Fig. 4).

\section{Effect of iron deprivation on germ-tube production}

Germ-tube formation by $C$. albicans in vitro can be conveniently assessed by incubating yeasts in serum for $2-3 \mathrm{~h}$. This procedure was used to test the effect of growth in different iron concentrations on the ability of six strains of $C$. albicans to produce hyphae. All of the

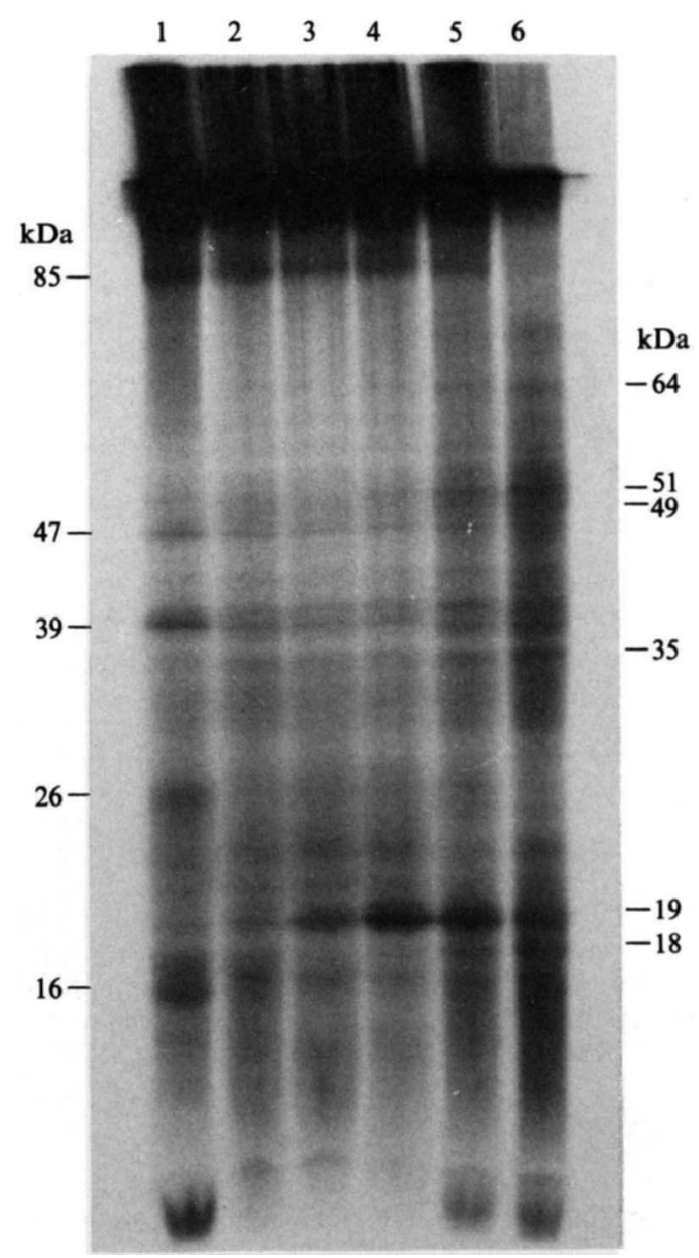

Fig. 4. SDS-PAGE of ${ }^{125}$ I-labelled proteins from C. albicans GDH 2346 grown in different concentrations of iron. Lanes 1 to 6 represent iron concentrations of $0.026 \mu \mathrm{M}, 0.05 \mu \mathrm{M}, 0.1 \mu \mathrm{M}, 0.2 \mu \mathrm{M}, 0.4 \mu \mathrm{M}$ and $0.8 \mu \mathrm{M}$, respectively. Bands were visualized by autoradiography.

strains formed significant numbers of germ tubes after $2 \mathrm{~h}$ in serum following growth in excess iron (Fig. 5). However, as the iron concentration in the growth medium was decreased, the ability of the yeasts to produce germ tubes in serum was inhibited by up to $93 \%$.

\section{Addition of transferrin to cultures}

C. albicans GDH 2346 was grown in medium containing $0.026,0.2$ or $0.8 \mu \mathrm{M}$-iron which had been supplemented with transferrin $(1 \mu \mathrm{M}$ or $20 \mu \mathrm{M})$ After $48 \mathrm{~h}$, the yield of yeasts, their adhesion to buccal cells and their sensitivity to Zymolyase were determined. A supplement of $1 \mu \mathrm{M}$ transferrin produced effects on all three parameters equivalent to that of adding $0.05-0.1 \mu \mathrm{M}$-iron to the growth medium, while a $20 \mu \mathrm{M}$ supplement had effects consistent with the addition of excess iron (data not shown). Similar results were obtained using lactoferrin or 


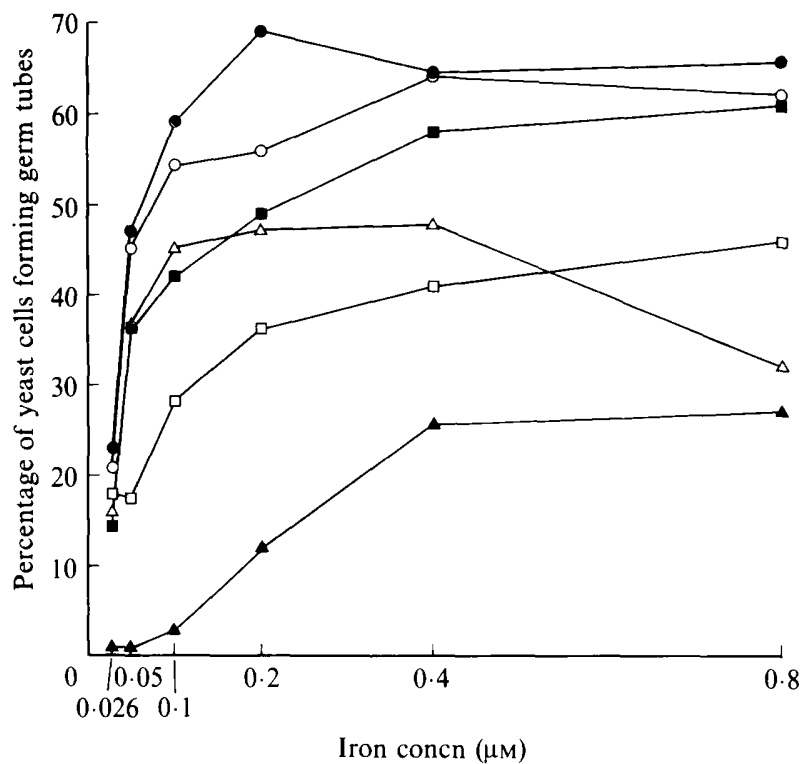

Fig. 5. Production of germ tubes in serum by $C$. albicans grown in different concentrations of iron. $O$, Strain GDH 2346; $\square$, strain GDH 2023; $\triangle$, strain GRI 681; , strain GRI 682; , strain NCPF 3153; $\boldsymbol{\Delta}$, 'outbreak' strain. The data represent mean values from three separate experiments.

ovotransferrin instead of transferrin. These findings suggest that, under the experimental conditions employed, the natural iron chelators constitute readily usable sources of iron that are $2 \cdot 5-5 \%$ saturated.

\section{Discussion}

Addition of transferrin, lactoferrin or ovotransferrin to culture media has been shown to inhibit growth of $C$. albicans in vitro (Kirkpatrick et al., 1971; Shiraishi \& Arai, 1979; Valenti et al., 1986). Such an inhibition was not observed in the present study. The defined medium used here, yeast nitrogen base with glucose, has a relatively low initial $\mathrm{pH}$ value of $5 \cdot 4$, and it seems probable that lack of growth inhibition was simply due to instability of the iron-chelator complex under these conditions. Transferrins have two iron-binding sites which respond differently to $\mathrm{pH}$ changes; iron is lost from one site at $\mathrm{pH}$ 6-7 whereas the other site is rather more stable, losing its iron at pH 5-6 (Bezkorovainy, 1987). An alternative explanation would be that the strains of C. albicans used in this study have particularly efficient iron-removal systems. Production of both hydroxamate- and phenolate-type siderophores by $C$. albicans has been reported (Ismail et al., 1985). However, preliminary experiments with our strains have revealed the presence of only the hydroxamate type in culture supernatants (S. P. Sweet \& L. J. Douglas, unpublished).
Direct interaction of transferrins with the cell surface of C. albicans has also been observed (Valenti et al., 1986) but this appears to be a feature of the hyphal and not the yeast form of the fungus (Page \& Odds, 1988).

Iron-restricted conditions were achieved without the use of a chelator by treating the growth medium with an ion-exchange resin, Chelex-100. This method has been used previously for studies of iron deprivation with both Gram-negative and Gram-positive bacteria (Kadurugamuwa et al., 1987). The protocol employed in that earlier investigation resulted in medium with an iron concentration of $0.23 \mu \mathrm{M}$, which was low enough to induce the synthesis of iron-regulated outer-membrane proteins in several Gram-negative isolates. Growth of Staphylococcus aureus, which synthesizes no such convenient markers of iron deprivation, was unaffected at this concentration, suggesting that its iron requirement is relatively low or that it is capable of rapid physiological adaptation to conditions of iron restriction (Kadurugamuwa et al., 1987). This may also be true of C. albicans since our results similarly show that the cell yield of most strains was unaffected, or even enhanced, at $0.2 \mu \mathrm{M}$-iron and that growth limitation required substantially lower $(<0.05 \mu \mathrm{M})$ concentrations.

The ability of $C$. albicans to adhere to host surfaces is considered an important virulence determinant of the organism (Douglas, 1987). With five of the six strains tested, growth in $0 \cdot 2-0 \cdot 4 \mu \mathrm{M}$-iron produced yeasts showing maximal adhesion to buccal epithelial cells. Adhesion of some of these strains (those isolated originally from active infections) is also enhanced following growth in high concentrations of certain sugars (McCourtie \& Douglas, 1984). Sugar-mediated regulation of adhesion is probably important in the mouth, where high concentrations of sucrose and other dietary sugars are commonly found. Our present results indicate that the availability of iron may represent an additional control mechanism in vivo, with relatively low concentrations promoting adhesion in most cases. Adhesion of one strain, $C$. albicans GDH 2023, was sharply increased at growthlimiting concentrations of iron. The exceptional behaviour of this organism is consistent with earlier studies (Critchley \& Douglas, 1987) which indicated that the adhesin-receptor mechanism by which it attaches to epithelial cells is different from that of the other strains.

Changes in yeast cell-surface composition, of which differences in adhesion are a reflection, were monitored with the muralytic enzyme preparation, Zymolyase, and by radio-iodination of surface proteins. Both methods indicated significant differences between iron-replete and iron-deficient organisms although with strain GDH 2346 , at least, changes in surface protein composition were quantitative rather than qualitative. A number of proteins appeared to be present in increased amounts in 
yeasts grown under iron-limiting conditions. They included a protein of molecular mass $47 \mathrm{kDa}$ which may correspond to the immunodominant $47 \mathrm{kDa}$ antigen shown by Matthews et al. (1988) to be present in the cytoplasm and wall of both yeast and mycelial forms of the fungus. This antigen is found in the sera of patients with systemic $C$. albicans infections and its detection has been used as the basis of a serological test for the diagnosis of systemic candidosis (Matthews \& Burnie, 1988). An antigen of $47 \mathrm{kDa}$ was also detected in another recent study of iron deprivation on the cell-wall protein composition of $C$. albicans (Paul et al., 1989). Here, growth at $37^{\circ} \mathrm{C}$ in different concentrations of iron $(0.35 \mu \mathrm{M}$ or $100 \mu \mathrm{M})$ had little effect on the expression of protein antigens visualized either with Coomassie blue or in Western blots using IgG from candidosis patients. However, $\operatorname{IgM}$ antibodies from patient sera revealed two antigens of $55 \mathrm{kDa}$ and $40 \mathrm{kDa}$ which appeared to be induced specifically in iron-deprived yeasts (Paul et al., 1989). No such specific induction was observed with the radiolabelling technique used in the present study although a protein of molecular mass $39 \mathrm{kDa}$ was among those present in increased amounts in iron-limited yeasts.

The ability of $C$. albicans to form hyphae has long been regarded as another important virulence characteristic which enables the fungus more easily to penetrate host tissue (Odds, 1988). In general, the physiological basis of the morphological transition from yeast to hypha is poorly understood but there is some evidence that hyphal development is affected by the environmental zinc concentration. For example, Soll and co-workers showed that zinc-starved yeasts took longer to initiate germ-tube formation than zinc-replete organisms (Soll, 1985). Similarly, Bedell \& Anderson (1985) reported that the chelating agent 1,10-phenanthroline inhibited mycelium production but that inhibition could be reversed by the addition of excess zinc. However, since phenanthroline has an affinity for both zinc and iron, reversal of inhibition due to competitive release of bound iron could not be discounted. We have now shown that severe iron restriction produces a loss of germ-tube-forming ability, indicating that iron is required for the morphological transition.

Overall, this study has demonstrated that expression of important virulence determinants by C. albicans is highly dependent on available iron and that expression in vivo may therefore be substantially different from that observed under conventional laboratory conditions. Relatively low iron concentrations of $0 \cdot 2-0.4 \mu \mathrm{M}$ produced maximal adhesion with most strains and allowed near-maximal germ-tube formation. Exposure of Gramnegative bacteria to such iron concentrations in vitro induces the synthesis of iron-regulated outer-membrane proteins which are known to be present in the same organisms growing in vivo (Kadurugamuwa et al., 1987). It is possible that these concentrations of iron most closely represent those available to $C$. albicans in vivo as a result of the contest between host defences and the ironscavenging mechanisms of the fungus.

This work was supported by a project grant from the Wellcome Trust. We are grateful to Dr D. J. Halls, Glasgow Royal Infirmary, for atomic absorption spectrometry.

\section{References}

Bedell, G. W. \& ANDERSON, R. V. (1985). Inhibition of the differentiation of Candida albicans by the chelator 1,10-phenanthroline. Mycopathologia 92, 161-167.

Bezkorovainy, A. (1987). Iron proteins. In Iron and Infection. Molecular, Physiological and Clinical Aspects, pp. 27-67. Edited by J. J. Bullen \& E. Griffiths. Chichester: John Wiley \& Sons

Brown, M. R. W. \& Williams, P. (1985). The influence of environment on envelope properties affecting survival of bacteria in infections. Annual Review of Microbiology 39, 527-556.

Bullen, J. J. \& Griffiths, E. (eds) (1987). Iron and Infection. Molecular, Physiological and Clinical Aspects. Chichester: John Wiley \& Sons.

Critchley, I. A. \& Douglas, L. J. (1987). Role of glycosides as epithelial cell receptors for Candida albicans. Journal of General Microbiology 133, 637-643.

Douglas, L. J. (1987). Adhesion of Candida species to epithelial surfaces. CRC Critical Reviews in Microbiology 15, $27-43$.

Douglas, L. J., Houston, J. G. \& McCourTiE, J. (1981). Adherence of Candida albicans to human buccal epithelial cells after growth on different carbon sources. FEMS Microbiology Letters 12, 241-243.

Finkelstein, R. A., Sciortino, C. V. \& McIntosh, M. A. (1983). Role of iron in microbe-host interactions. Reviews of Infectious Diseases $\mathbf{5}$, S759-S777.

Holmes, R. K. \& Russell, L. M. (1983). Role of iron in regulating synthesis of bacterial toxins. In Microbiology 1983, pp. 359-362. Edited by D. Schlessinger. Washington, DC: American Society for Microbiology.

HolzberG, M. \& ARTIS, W. M. (1983). Hydroxamate siderophore production by opportunistic and systemic fungal pathogens. Infection and Immunity 40, 1134-1139.

Ismail, A., Bedell, G. W. \& Lupan, D. M. (1985). Siderophore production by the pathogenic yeast, Candida albicans. Biochemical and Biophysical Research Communications 130, 885-891.

Kadurugamuwa, J. L., Anwar, H., Brown, M. R. W., Shand, G. H. \& WARD, K. H. (1987). Media for study of growth kinetics and envelope properties of iron-deprived bacteria. Journal of Clinical Microbiology 25, 849-855.

KirkPatrick, C. H., Green, I., Rich, R. R. \& Schade, A. L. (1971). Inhibition of growth of Candida albicans by iron-unsaturated lactoferrin: relation to host-defense mechanisms in chronic mucocutaneous candidiasis. Journal of Infectious Diseases 124, 539-544.

McCourtie, J. \& Douglas, L. J. (1984). Relationship between cell surface composition, adherence and virulence of Candida albicans. Infection and Immunity 45, 6-12.

Matthews, R. \& BURnie, J. P. (1988). Diagnosis of systemic candidiasis by an enzyme-linked dot immunobinding assay for a circulating immunodominant 47 -kilodalton antigen. Journal of Clinical Microbiology 26, 459-463

Matthews, R., Wells, C. \& Burnie, J. P. (1988). Characterisation and cellular localisation of the immunodominant $47-\mathrm{Kda}$ antigen of Candida albicans. Journal of Medical Microbiology 27, 227-232.

NeILANDS, J. B. (1981). Microbial iron compounds. Annual Review of Biochemistry 50, 715-731. 
NeIlands, J. B. (1982). Microbial envelope proteins related to iron. Annual Review of Microbiology 36, 285-309.

ODDs, F. C. (1988). Candida and Candidosis, 2nd edn. London: Baillière Tindall.

PAGe, S. \& OdDS, F. C. (1988). Binding of plasma proteins to Candida species in vitro. Journal of General Microbiology 134, 2693-2702.

Paul, T. R., Smith, S. N. \& Brown, M. R. W. (1989). Effect of iron depletion on cell-wall antigens of Candida albicans. Journal of Medical Microbiology 28, 93-100.
ShIRAISHI, A. \& ARAI, T. (1979). Antifungal activity of transferrin. Sabouraudia 17, 79-83.

Soll, D. R. (1985). The role of zinc in Candida dimorphism. In Current Topics in Medical Mycology, vol. 1, pp. 258-285. Edited by M. R. McGinnis. New York: Springer-Verlag.

Valenti, P., Visca, P., ANTONINI, G. \& Orsi, N. (1986). Interaction between lactoferrin and ovotransferrin and Candida cells. FEMS Microbiology Letters 33, 271-275. 